\title{
Interaction Effect Between Breast Density and Reproductive Factors on Breast Cancer Risk in Korean Population
}

ORIGINAL

ARTICLE

\author{
Se-Eun Lim ${ }^{1}$, HyoJin Ahn' ${ }^{1}$, Eun Sook Lee ${ }^{2,3}$, Sun-Young Kong ${ }^{2,3}$, So-Youn Jung ${ }^{2,3}$, Seeyoun Lee ${ }^{2,3}$, Han-Sung Kang ${ }^{2,3}$, \\ Eun-Gyeong Lee ${ }^{3}$, Jai Hong Han $^{3}$, Boyoung Park ${ }^{1,2}$ \\ ${ }^{1}$ Department of Medicine, Hanyang University College of Medicine, Seoul, ${ }^{2}$ Research Institute, National Cancer Center, ${ }^{3}$ National Cancer Center \\ Hospital, Goyang, Korea
}

\begin{abstract}
Background: This study was conducted to explore the effect of known risk factors, focusing on risk factors including age at menarche, age at menopause, number of children, family history of breast cancer, and age at first birth according to breast density, in consideration of interaction among East-Asian women.

Methods: Case-control study with 2,123 cases and 2,121 controls with mammographic density was conducted. Using the mammographic film, breast density was measured using Breast Imaging-Reporting and Data System. To identify the association of selected reproductive factors including age at menarche, age at menopause, number of children, family history of breast cancer, and age at first birth according to breast density, stratified analysis was conducted according to breast density groups and interaction effects was assessed. The results were presented with adjusted OR and 95\% Cls.

Results: Significant interaction effect between age at first birth and breast density on breast cancer $(P=0.048)$ was observed. Women with age at first birth $\geq 28$ years old showed increased breast cancer risk in extremely dense breast group $(\geq 75 \%)(O R=1.627$, $95 \% \mathrm{Cl}=1.190-2.226)$. However, women with fatty breast $(<50 \%)$ and heterogeneously dense breast $(50 \%-75 \%)$ did not show an increased association. Age at menarche, age at menopause, number of children, and family history of breast cancer did not show significant interaction with breast cancer and similar risk patterns were observed.

Conclusions: Age at first birth showed significant interaction with breast density on breast cancer risk. Further studies considering biologically plausable model between exposure, intermediate outcomes and breast cancer risk with prospective design need to be undertaken in East Asian women.
\end{abstract}

(J Cancer Prev 2019;24:26-32)

Key Words: Breast neoplasms, Breast density, Reproductive history

\section{INTRODUCTION}

Breast cancer has been the most commonly diagnosed cancer among women in Korea. In 2016, 21,747 women were newly diagnosed with breast cancer which is around 20 percent of all types of estimated new cancer for Korean women [1]. Not only in Korea but also worldwide, breast cancer was the most common cancer and leading cause of death in women [2]. Previous researches have introduced several risk factors [3] and also explained that due to the changes in lifestyle and reproductive risk factors, breast cancer incident rate has been rapidly increasing, especially in Asian countries [4].

Mammographic density is a measure of dense breast tissue based on radiological mammogram. Mammographic breast density is well known and one of the most important non-modifiable risk factors of breast cancer, which increases breast cancer risk by about five times for those with percent density $\geq 75 \%$ compared to women with percent density $<5 \%$ [5]. Several studies have revealed that the effect of mammographic density as a non-modifiable factor could be

Received March 21, 2019, Accepted March 22, 2019

Correspondence to: Boyoung Park

E-mail: hayejine@hanmail.net, ORCID: Boyoung Park, https://orcid.org/0000-0003-1902-3184

Copyright (C) 2019 Korean Society of Cancer Prevention

(c) This is an Open Access article distributed under the terms of the Creative Commons Attribution Non-Commercial License (http://creativecommons.org/licenses/by-nc/4.0) which permits unrestricted non-commercial use, distribution, and reproduction in any medium, provided the original work is properly cited. 
modified by other known breast cancer risk factors, such as family history, reproductive factors, behavioral factors, or body mass index (BMI) [6-10]. Moreover, studies also showed breast density is also associated with other breast cancer risk factors, especially with reproductive factors [11-13].

Considering that the non-amendable factors are considered as the effect modifier and amendable factors as main effect variable from the preventive point [14], the effects of known breast cancer risk factors need to be accessed by breast density, considering the interaction between known risk factors and breast density on breast cancer risk. However, to the best of the authors' knowledge, that kind of approach has been conducted rarely. Rather, the effect of mammographic density was assessed by other risk factors. Therefore, this study was conducted to explore the effect of known risk factors, focusing on risk factors including age at menarche, age at menopause, number of children, family history of breast cancer, and age at first birth according to breast density, in consideration of interaction among East-Asian women.

\section{MATERIALS AND METHODS}

\section{Study population}

Participants of this study were recruited from those who visited National Cancer Center in South Korea. Cases were females aged 20 or more who confirmed ductal carcinoma in situ or invasive breast cancer histologically between February 2014 and January 2018. Controls consisted of females aged 20 or more free of cancer who visited for regular health check-up from March 2014 to September 2016. After obtaining informed consent, they were asked to participate in the study. Face to face interviews were conducted by trained interviewers. Among 4,690 females recruited, 4,244 females including 2,123 cases and 2,121 controls with mammographic density information from the National Cancer Center were included in the analysis. In the case of breast cancer, those whose mammographic results before breast cancer diagnosis were considered. This study was approved by the National Cancer Center Institutional Review Board (IRB No. NCC 2015-0177). All procedures were performed in accordance with the Declaration of Helsinki 7th.

Information collected from the participants consisted of established or suspected risk factors of breast cancer including age, BMI, reproductive factors (age at menarche, age at menopause, age at first birth, number of children, and breast feeding), oral contraceptive use, hormone replacement therapy after menopause, first degree relatives ever diagnosed with breast cancer, alcohol drinking, tobacco smoking, and exercise [15] through structured questionnaire. Among them, we focused on the age at menarche, age at menopause, number of children, family history of breast cancer, and age at first birth. Age at menarche was classified as $<$ 15 and $\geq 15$ years old. Age at menopause was classified as premenopausal, $<50$, and $\geq 50$ years old. The number of children was classified as 0,1 , and 2 or more. Age at first birth among parous women was classified as $<28$ and $\geq 28$ years old. Family history of breast cancer was measured as whether the participants have their first relative diagnosed with breast cancer.

\section{Breast density measurement}

Using the mammographic film, trained radiologists determined breast density using Breast Imaging-Reporting and Data System (BI-RADS). Breast density measured by BI-RADS is classified by 4 stages; BI-RADS 1 (0\%-25\%): mostly fatty breast, BI-RADS 2 (25\%-50\%): fibroglandular breast, BI-RADS 3 (50\%-75\%): heterogeneously dense breast, and BI-RADS 4 (75\%-100\%): extremely dense breast. Due to short number of patients with fatty breast, BI-RADS breast density 1 and 2 were merged into one category as fatty breast $(<50 \%)$. Thus, final classification of breast density included 1 and $2(<50 \%), 3(50 \%-75 \%)$, and 4 (75\%-100\%).

\section{Statistical analysis}

The characteristics of the breast cancer cases and controls were compared using a t-test for continuous variable and the chi-square test for categorical variables. In addition, the basic characteristics of cases and controls were compared according to breast density group separately ( $<50 \%, 50 \%-75 \%, \geq 75 \%)$. The association between breast density, selected reproductive factors and breast cancer were analyzed using multiple logistic regression, adjusting for the covariates including age, BMI, smoking status, duration of alcohol drinking, and exercise and presented as adjusted OR (aOR) and 95\% CIs. Missing variables were treated as dummies. To identify the association of selected reproductive factors including age at menarche, age at menopause, number of children, family history of breast cancer, and age at first birth according to breast density, stratified analysis was conducted according to breast density groups. Heterogeneity of association between breast density groups was assessed using Cochran's $Q$ test [16]. The interaction effects between selected reproductive factors and breast density on breast cancer were estimated by including interaction term in the multiple logistic regression model. All analyses were conducted using SAS ver. 9.4 (SAS Institute, Cary, NC, USA). 


\section{RESULTS}

Table 1 presents baseline characteristics of breast cancer cases and controls. The average age for case was 46.86 years and 48.51 years for controls $(P<0.0001)$. Compared with controls, cases had higher BMI $(P=0.0001)$, were more often nulliparous and older at first giving birth $(P<0.0001)$, were younger at the first menstrual period ( $P<0.0001)$, and had family history of breast cancer more $(P=0.0100)$. Cases and controls did not significantly differ in age at menopause and number of children. However, when stratified by breast density ( $<50 \%, 50 \%-75 \%$, $\geq 75 \%$ ), all considered variables, except BMI showed significantly different distribution $(P<0.05)$.
Associations between breast density, reproductive factors and breast cancer were demonstrated in the Table 2. The increased breast density category was likely associated with breast cancer risk ( $\mathrm{aOR}=1.226,95 \% \mathrm{CI}=0.994-1.592)$ for those with breast density $>75 \%$ compared with those with $<50 \%$. In addition, late age at first birth ( $\geq 28$ years old) and family history of breast cancer were associated with increased breast cancer risk significantly (aOR $=1.198,95 \% \mathrm{CI}=1.031-1.392 ; \mathrm{aOR}=1.444$, $95 \% \mathrm{CI}=1.188-1.755)$. Conversely, late age at menarche $(\geq 15$ years old) and late age at menopause compared to premenopausal showed significant decreased association with breast cancer.

Table 3 demonstrates the association between selected risk factors and breast cancer, stratified by breast density groups and

Table 1. Characteristics of case and controls by selected reproductive risk factors

\begin{tabular}{|c|c|c|c|c|c|c|c|c|c|c|}
\hline \multirow{2}{*}{ Risk factor } & \multicolumn{2}{|c|}{ Total } & \multirow{2}{*}{$P$-value } & \multicolumn{2}{|c|}{$\begin{array}{l}\text { BI-RADS } 1 \text { and } 2 \\
(<50 \%)\end{array}$} & \multicolumn{2}{|c|}{ BI-RADS 3 (50\%-75\%) } & \multicolumn{2}{|c|}{ BI-RADS $4(\geq 75 \%)$} & \multirow{2}{*}{$P$-value } \\
\hline & Case & Control & & Case & Control & Case & Control & Case & Control & \\
\hline Age (yr) & $46.86 \pm 9.35$ & $48.51 \pm 9.93$ & $<0.0001$ & & & & & & & $<0.0001$ \\
\hline$<30$ & $39(1.8)$ & $85(4.0)$ & $<0.0001$ & $3(1.4)$ & $0(0)$ & $8(0.8)$ & $2(0.2)$ & $25(4.0)$ & $14(3.3)$ & \\
\hline $30-39$ & $436(20.5)$ & $213(10.0)$ & & $27(12.5)$ & $3(1.1)$ & $175(18.3)$ & $33(3.8)$ & $175(27.7)$ & $55(12.8)$ & \\
\hline $40-49$ & $864(40.7)$ & $864(40.7)$ & & $49(22.7)$ & $43(15.9)$ & $377(39.4)$ & $353(41.0)$ & $312(49.4)$ & $251(58.4)$ & \\
\hline $50-59$ & $572(26.9)$ & $640(30.2)$ & & $74(34.3)$ & $97(35.9)$ & $308(32.2)$ & $348(40.4)$ & $106(16.8)$ & $91(21.2)$ & \\
\hline $60-69$ & $182(8.6)$ & $260(12.3)$ & & $53(24.5)$ & $107(39.6)$ & $79(8.3)$ & $111(12.9)$ & $13(2.1)$ & $13(3.0)$ & \\
\hline$\geq 70$ & $28(1.3)$ & $36(1.7)$ & & $10(4.6)$ & $20(7.4)$ & $9(0.9)$ & $10(1.2)$ & $0(0)$ & $1(0.2)$ & \\
\hline \multicolumn{3}{|c|}{ Age at menarche (yr) } & $<0.0001$ & & & & & & & 0.0016 \\
\hline$<15$ & $1,520(71.6)$ & $1,212(57.1)$ & & $118(54.6)$ & $99(36.7)$ & $658(68.8)$ & $442(51.3)$ & $502(79.6)$ & $276(64.2)$ & \\
\hline$\geq 15$ & $574(27.0)$ & $706(33.3)$ & & $93(43.1)$ & $136(50.4)$ & $281(29.4)$ & $322(37.4)$ & $123(19.5)$ & $120(27.9)$ & \\
\hline Unknown & $29(1.4)$ & $184(8.7)$ & & $5(2.3)$ & $35(13.0)$ & $17(1.8)$ & $97(11.3)$ & $6(1.0)$ & $34(7.9)$ & \\
\hline \multicolumn{3}{|c|}{ Age at menopause (yr) } & 0.0518 & & & & & & & $<0.0001$ \\
\hline Premenopausa & $1,320(62.2)$ & $1,130(53.9)$ & & $59(27.3)$ & $42(15.6)$ & $548(57.3)$ & $376(43.9)$ & $511(81.0)$ & $305(71.8)$ & \\
\hline$<50$ & $390(18.4)$ & $475(22.6)$ & & $65(30.1)$ & $93(34.4)$ & $199(20.8)$ & $233(27.2)$ & $69(10.9)$ & $65(15.3)$ & \\
\hline$\geq 50$ & $411(19.4)$ & $493(23.5)$ & & $92(42.6)$ & $135(50.0)$ & $209(21.9)$ & $248(28.9)$ & $51(8.1)$ & $55(12.9)$ & \\
\hline \multicolumn{3}{|c|}{ Number of children } & 0.8015 & & & & & & & $<0.0001$ \\
\hline 0 & $358(16.9)$ & $285(13.4)$ & & $10(4.6)$ & $10(3.7)$ & $146(15.3)$ & $61(7.08)$ & $143(22.66)$ & $72(16.7)$ & \\
\hline 1 & $420(19.8)$ & $352(16.6)$ & & $30(13.9)$ & $32(11.9)$ & $175(18.3)$ & $130(15.10)$ & $162(25.67)$ & $76(17.7)$ & \\
\hline$\geq 2$ & $1,317(62.0)$ & $1,286(60.6)$ & & $172(79.6)$ & $200(74.1)$ & $618(64.6)$ & $573(66.55)$ & $320(50.71)$ & $237(55.1)$ & \\
\hline Unknown & $28(1.3)$ & $198(9.3)$ & & $4(1.9)$ & $28(10.4)$ & $17(1.8)$ & $97(11.27)$ & $6(0.95)$ & $45(10.5)$ & \\
\hline \multicolumn{3}{|c|}{ Age at first birth (yr) } & $<0.0001$ & & & & & & & $<0.0001$ \\
\hline$<28$ & $822(38.7)$ & $871(41.1)$ & & $133(61.6)$ & $144(53.3)$ & $394(41.2)$ & $387(44.9)$ & $164(26.0)$ & $153(35.6)$ & \\
\hline$\geq 28$ & $910(42.9)$ & $734(34.6)$ & & $69(31.9)$ & $79(29.3)$ & $398(41.6)$ & $298(34.6)$ & $315(49.9)$ & $155(36.0)$ & \\
\hline Nulliparous & $358(16.9)$ & $285(13.4)$ & & $10(4.6)$ & $10(3.7)$ & $146(15.3)$ & $61(7.1)$ & $143(22.7)$ & $72(16.7)$ & \\
\hline Unknown & $33(1.6)$ & $231(10.9)$ & & $4(1.9)$ & $37(13.7)$ & $18(1.9)$ & $115(13.4)$ & $9(1.4)$ & $50(11.6)$ & \\
\hline \multicolumn{3}{|c|}{ Breast cancer in first-degree relatives } & 0.0100 & & & & & & & 0.0173 \\
\hline 0 & $1,597(75.2)$ & $1,633(77.0)$ & & $163(75.5)$ & $212(78.5)$ & $719(75.2)$ & $667(77.8)$ & $473(75.0)$ & $345(81.2)$ & \\
\hline$\geq 1$ & $317(14.9)$ & $228(10.7)$ & & $37(17.1)$ & $24(8.9)$ & $143(15.0)$ & $80(9.3)$ & $85(13.5)$ & $29(6.8)$ & \\
\hline Unknown & $209(9.8)$ & $240(11.3)$ & & $16(7.4)$ & $34(12.6)$ & $94(9.8)$ & $110(12.8)$ & $73(11.6)$ & $51(12.0)$ & \\
\hline \multicolumn{3}{|c|}{ Body mass index $\left(\mathrm{kg} / \mathrm{m}^{2}\right)$} & 0.0001 & & & & & & & 0.4964 \\
\hline$<25$ & $1,572(74.0)$ & $1,581(74.5)$ & & $114(52.8)$ & $159(58.9)$ & $664(69.5)$ & $620(72.3)$ & $560(88.7)$ & $369(86.8)$ & \\
\hline$\geq 25$ & $484(23.5)$ & $355(16.7)$ & & $91(42.1)$ & $81(30.0)$ & $259(27.1)$ & $153(1.9)$ & $57(9.0)$ & $28(6.6)$ & \\
\hline Unknown & $65(2.5)$ & $162(7.6)$ & & $11(5.1)$ & $30(11.1)$ & $33(3.5)$ & $84(1.1)$ & $14(2.2)$ & $28(6.6)$ & \\
\hline
\end{tabular}

Values are presented as Mean \pm SD or number (\%). BI-RADS, Breast Imaging-Reporting and Data System. 
Table 2. ORs and $95 \%$ CIs of breast cancer for breast density and selected risk factors

\begin{tabular}{|c|c|c|c|c|}
\hline \multirow[b]{2}{*}{ Risk factor } & \multicolumn{4}{|c|}{ OR $(95 \% \mathrm{CI})$} \\
\hline & & $\begin{array}{c}\text { Age } \\
\text { adjusted }\end{array}$ & & $\begin{array}{l}\text { Uultivariate } \\
\text { adjusted }^{\mathrm{a}}\end{array}$ \\
\hline \multicolumn{5}{|l|}{ Breast density } \\
\hline BI-RADS 1 and $2(<50 \%)$ & & 1 & & 1 \\
\hline BI-RADS $3 \quad(50 \%-75 \%)$ & 1.057 & $7(0.855-1.307)$ & 1.110 & $(0.886-1.391)$ \\
\hline BI-RADS 4 ( $\geq 75 \%)$ & 1.102 & $2(0.866-1.402)$ & 1.226 & $6(0.994-1.592)$ \\
\hline \multicolumn{5}{|l|}{ Age at menarche $(\mathrm{yr})$} \\
\hline$<15$ & & 1 & & 1 \\
\hline$\geq 15$ & 0.647 & $7(0.564-0.742)$ & 0.681 & $(0.588-0.789)$ \\
\hline \multicolumn{5}{|l|}{ Age at menopause (yr) } \\
\hline Premenopausal & & 1 & & 1 \\
\hline$<50$ & 0.695 & $(0.592-0.816)$ & 0.812 & (0.679-0.971) \\
\hline$\geq 50$ & 0.703 & $(0.598-0.825)$ & 0.752 & $(0.626-0.904)$ \\
\hline \multicolumn{5}{|l|}{ Number of children } \\
\hline 0 & 1.222 & $(1.024-1.458)$ & 1.167 & $7(0.962-1.417)$ \\
\hline 1 & 1.178 & $(1.002-1.386)$ & 1.128 & $3(0.949-1.341)$ \\
\hline 2 or more & & 1 & & 1 \\
\hline \multicolumn{5}{|l|}{ Age at first birth (yr) } \\
\hline$<28$ & & 1 & & 1 \\
\hline$\geq 28$ & 1.326 & $(1.156-1.521)$ & 1.198 & $(1.031-1.392)$ \\
\hline \multicolumn{5}{|c|}{ Family history of breast cancer } \\
\hline No history & & 1 & & 1 \\
\hline 1st degree & 1.438 & $(1.196-1.730)$ & 1.444 & $(1.188-1.755)$ \\
\hline
\end{tabular}

BI-RADS, Breast Imaging-Reporting and Data System. adjusted for body mass index, smoke, drink duration, exercise, age, age at menarche, age at menopause, number of child, number of first-degree relatives with breast cancer.

interaction effect between selected reproductive factors and breast density on breast cancer. We identified statistically significant interaction effect between age at first birth and breast density on breast cancer $(P=0.048)$. Women with older age at first birth ( $\geq 28$ years old) showed increased breast cancer risk in extremely dense breast group $(\geq 75 \%)$ with $\mathrm{OR}$ of $1.627(95 \% \mathrm{CI}=$ 1.190-2.226). However, women with fatty breast $(<50 \%)$ and heterogeneously dense breast $(50 \%-75 \%)$ did not show such an increased association. Age at menarche, age at menopause, number of children, and family history of breast cancer did not show significant interaction with breast cancer $(P>0.05)$ and similar risk patterns were observed as shown in the Table 2 .

\section{DISCUSSION}

In this study with 2,123 breast cancer cases and 2,121 controls, most of the reproductive risk factors including age at menarche, age at menopause, number of children, and family history of breast cancer did not show interaction with breast density on breast cancer risk. However, age at first birth showed significant interaction with breast density on breast cancer risk - later age at first birth increased breast cancer risk in women with dense breast $(\geq 75 \%)$ but not increased risk in women with breast density $<75 \%(<50 \%$ and $50 \%-75 \%)$.

Previous studies regarding the interaction effect between known risk factors and breast density on breast cancer risk showed various results. A previous study showed that parity and breast density had the interaction effect on breast density increment effect in parous women but not in nulliparous women. However, other reproductive and lifestyle risk factors including age at first birth did not modify the effect of breast density [6]. The modifying effect of breast density for the parity was replicated in another study [10]. In this study, we observed only borderline significance in the interaction effect between parity and breast density on breast cancer risk. To compare our result with that of previous studies, we re-analyzed data applying same approaches with most previous studies - breast density as effect variable and other reproductive factors as effect modifiers (Appendix Table 1). In our study, we identified increased breast cancer risk in those with breast density 50\%-75\% among nulliparious women and among parous women, the increment pattern of breast cancer was not prominent according to higher breast density. In addition, unlike a previous study [6], we found an interaction with breast density only in age at first birth. In this study, the wide age range of study participants from $<30$ years old to $\geq 70$ years old, rapid changes in reproductive factors in East Asia, especially in Korea [17] and age effect on breast density [18] could affect the interaction effect between breast density and age at first birth on breast cancer. Otherwise, the relationship between breast density and reproductive factors could contribute to the result [11,12].

Other studies showed that women with family history of breast cancer had a higher risk of breast cancer as breast density increased than women without family history in both whites and Asians [7,9]. This is consistent with our results (Appendix Table 1)increment of breast cancer risk as breast density increased in those with family history of breast cancer, but not in those without family history. Heritability of mammographic density within family members has been well demonstrated $[19,20]$ and some studies suggested that mammographic density could explain the effect of family history on breast cancer risk partially [21].

Other studies also showed that the effect of mammographic density was not modified by BMI or [8] the effect of breast density was more prominent in hormone replacement therapy users 
Table 3. ORs and $95 \% \mathrm{CIs}^{\mathrm{a}}$ of breast cancer for selected risk factors by breast density groups and their interaction effects

\begin{tabular}{|c|c|c|c|c|c|c|c|c|c|c|}
\hline \multirow[b]{2}{*}{ Variable } & \multicolumn{3}{|c|}{ BI-RADS 1 and $2(<50 \%)$} & \multicolumn{3}{|c|}{ BI-RADS $3 \quad(50 \%-75 \%)$} & \multicolumn{3}{|c|}{ BI-RADS 4 ( $\geq 75 \%)$} & \multirow{2}{*}{$-\underset{\text { interaction }}{P}$} \\
\hline & $\begin{array}{c}\text { No. of } \\
\text { case/ } \\
\text { control }\end{array}$ & OR $(95 \% \mathrm{CI})$ & $P$-value & $\begin{array}{c}\text { No. of } \\
\text { case/ } \\
\text { control }\end{array}$ & OR $(95 \% \mathrm{CI})$ & $P$-value & $\begin{array}{c}\text { No. of } \\
\text { case/ } \\
\text { control }\end{array}$ & OR $(95 \% \mathrm{CI})$ & $P$-value & \\
\hline \multicolumn{11}{|c|}{ Age at menarche $(\mathrm{yr})$} \\
\hline$<15$ & $118 / 99$ & $1.176(0.765-1.809)$ & 0.46 & $658 / 442$ & $1.375(1.103-1.715)$ & 0.0047 & $502 / 276$ & $1.528(1.113-2.096)$ & 0.0086 & 0.6806 \\
\hline$\geq 15$ & $93 / 136$ & 1 & & $281 / 322$ & 1 & & $123 / 120$ & 1 & & \\
\hline \multicolumn{11}{|c|}{ Age at menopause (yr) } \\
\hline Premenopausal & $59 / 42$ & 1 & & $548 / 380$ & 1 & & $511 / 310$ & 1 & & 0.9109 \\
\hline$<50$ & $65 / 93$ & $1.621(0.822-3.195)$ & 0.1633 & $199 / 233$ & $0.949(0.710-1.267)$ & 0.7211 & $69 / 65$ & $0.858(0.563-1.308)$ & 0.4767 & \\
\hline$\geq 50$ & $92 / 135$ & $1.746(0.852-3.577)$ & 0.128 & $209 / 248$ & $1.092(0.794-1.501)$ & 0.5899 & $51 / 55$ & $0.865(0.513-1.458)$ & 0.5855 & \\
\hline \multicolumn{11}{|c|}{ Number of children } \\
\hline 0 & $10 / 10$ & $0.547(0.195-1.532)$ & 0.251 & $146 / 60$ & $1.823(1.287-2.582)$ & 0.0007 & $143 / 72$ & $1.085(0.747-1.576)$ & 0.6676 & \\
\hline 1 & $30 / 32$ & $0.771(0.424-1.403)$ & 0.3947 & $175 / 127$ & $1.141(0.868-1.499)$ & 0.3439 & $162 / 74$ & $1.442(1.027-2.023)$ & 0.0344 & 0.0921 \\
\hline 2 or more & $172 / 200$ & 1 & & $618 / 573$ & 1 & & $320 / 234$ & 1 & & \\
\hline \multicolumn{11}{|c|}{ Age at first birth (yr) } \\
\hline$<28$ & $133 / 144$ & 1 & & $394 / 387$ & 1 & & $164 / 153$ & 1 & & 0.0048 \\
\hline$\geq 28$ & $69 / 79$ & $0.781(0.493-1.236)$ & 0.2904 & $398 / 298$ & $1.087(0.865-1.365)$ & 0.4734 & $315 / 155$ & $1.627(1.190-2.226)$ & 0.0023 & \\
\hline \multicolumn{11}{|c|}{ Family history of breast cancer } \\
\hline No & $163 / 212$ & 1 & & $719 / 671$ & 1 & & $473 / 349$ & 1 & & 0.7925 \\
\hline 1st degree & $37 / 24$ & $2.140(1.158-3.954)$ & 0.0152 & $143 / 80$ & $1.653(1.215-2.249)$ & 0.0014 & $85 / 30$ & $1.690(1.064-2.685)$ & 0.0261 & \\
\hline
\end{tabular}

BI-RADS: Breast Imaging-Reporting and Data System. ${ }^{a}$ Adjusted for body mass index, smoke, drink duration, exercise, age, age at menarche, age at menopause, number of child, number of first-degree relatives with breast cancer.

$[6,22]$. However, another study showed opposite results that the effect of mammography was not different by menopausal status or in hormone replacement therapy use [23]. This study only focused on the reproductive factors and breast density on breast cancer risk and not considered lifestyle related factors such as BMI, oral contraceptive use, and hormone replacement therapy. Thus, other risk factors need to be further considered.

Although breast density is one of the most important risk factors of breast cancer [15], the effect of breast density itself in this study was not significant and the point estimate was much lower than previous meta-analysis which showed about four fold increment of breast cancer risk [5]. This meta-analysis applied breast density $<5 \%$ as reference group but in this study those with density $<50 \%$ was a reference due to a limited number of participants with fatty breast. Thus, higher cut-off for the reference group could result non-significant result. When breast density was not considered as modifiable factors, the comprehensive effect of selected reproductive factors on breast cancer was comparable with previous studies [15].

The limitations of this study are as follows; First, the existence of selection bias should be considered. The study population was selected from single institute and would not represent target population. However, the comparability between cases and controls would be better because they were recurited from same hospital. Second, information bias such as recall-bias could affect measurement of variables throught questionnaires. Third, although studies measured breast density as contunous variables, this study applied BI-RADS classification as categorical variable because BI-RADS classification was widely available in Korea because National Cancer Screening Program in Korea uses BI-RADS system to report the results. Fourth, despite of important effect of age on breast density, we did not match age between cases and controls as a whole and in each age group to include more number of participants. To minimize the age effect on results, we adjusted for age in all analysis but it might not be enough to control it. In addition, the non-significant interaction effects between reproductive factors and and breast density on breast cancer risk could be attributed to the low power of this study.

Despite of these limitations, this is a first study to report the interaction between reproductive factors and breast density on breast cancer risk in Korean female population. In addition, the approach of this study that utilizes breast density as an effect modifier would be a novel approach compared with previous studies which applied breast density as an only exposure variable. Considering that the breast density could be an intermediate factor between reproductive factors and breast cancer $[11,12]$, and the interaction among heretability, known 
breast cancer risk especially reproductive risk factors and breast density is under investigation, further studies considering biologically plausable model between exposure, intermediate outcomes and breast cancer risk with prospective design need to be investigated in East Asian women.

\section{ACKNOWLEDGMENTS}

The present study was supported by a research grant in 2017 by the Korean Foundation for Cancer Research, Seoul, Korea.

\section{CONFLICTS OF INTEREST}

No potential conflicts of interest were disclosed.

\section{REFERENCES}

1. National Cancer Information Center. 2016 National Cancer Statistics, Korea. https://www.cancer.go.kr/lay1/bbs/S1T674C680/B/ $26 /$ view.do? article_seq $=21129 \& \mathrm{cpage}=2 \&$ rows $=12 \&$ condition $=\& k$ eyword $=\& r n=21>$. Accessed March 16, 2019.

2. Bray F, Ferlay J, Soerjomataram I, Siegel RL, Torre LA, Jemal A. Global cancer statistics 2018: GLOBOCAN estimates of incidence and mortality worldwide for 36 cancers in 185 countries. CA Cancer J Clin 2018;68:394-424.

3. Sun YS, Zhao Z, Yang ZN, Xu F, Lu HJ, Zhu ZY, et al. Risk factors and preventions of breast cancer. Int J Biol Sci 2017;13:1387-97.

4. Youlden DR, Cramb SM, Yip CH, Baade PD. Incidence and mortality of female breast cancer in the Asia-Pacific region. Cancer Biol Med 2014;11:101-15.

5. McCormack VA, dos Santos Silva I. Breast density and parenchymal patterns as markers of breast cancer risk: a meta-analysis. Cancer Epidemiol Biomarkers Prev 2006;15:1159-69.

6. Yaghjyan L, Colditz GA, Rosner B, Tamimi RM. Mammographic breast density and breast cancer risk: interactions of percent density, absolute dense, and non-dense areas with breast cancer risk factors. Breast Cancer Res Treat 2015;150:181-9.

7. Maskarinec G, Nakamura KL, Woolcott CG, Conroy SM, Byrne C, Nagata $C$, et al. Mammographic density and breast cancer risk by family history in women of white and Asian ancestry. Cancer Causes Control 2015:26:621-6.

8. Conroy SM, Woolcott CG, Koga KR, Byrne C, Nagata C, Ursin G, et al. Mammographic density and risk of breast cancer by adiposity: an analysis of four case-control studies. Int J Cancer 2012;130: 1915-24.
9. Maskarinec G, Dartois L, Delaloge S, Hopper J, Clavel-Chapelon F, Baglietto L. Tumor characteristics and family history in relation to mammographic density and breast cancer: the French E3N cohort. Cancer Epidemiol 2017;49:156-60.

10. Woolcott CG, Koga K, Conroy SM, Byrne C, Nagata C, Ursin G, et al. Mammographic density, parity and age at first birth, and risk of breast cancer: an analysis of four case-control studies. Breast Cancer Res Treat 2012;132:1163-71.

11. Yaghjyan L, Colditz GA, Rosner B, Bertrand KA, Tamimi RM. Reproductive factors related to childbearing and mammographic breast density. Breast Cancer Res Treat 2016;158:351-9.

12. Sung H, Ren J, Li J, Pfeiffer RM, Wang Y, Guida JL, et al. Breast cancer risk factors and mammographic density among high-risk women in urban China. NPJ Breast Cancer 2018;4:3.

13. Andersen ZJ, Baker JL, Bihrmann K, Vejborg I, Sørensen TI, Lynge E. Birth weight, childhood body mass index, and height in relation to mammographic density and breast cancer: a register-based cohort study. Breast Cancer Res 2014;16:R4.

14. Szklo M, Nieto FJ. Epidemiology: beyond the basics. 2nd ed. Sudbury, Massachussets, Jones and Bartlett, 2007.

15. Key T], Verkasalo PK, Banks E. Epidemiology of breast cancer. Lancet Oncol 2001;2:133-40.

16. Higgins JP, Thompson SG, Deeks JJ, Altman DG. Measuring inconsistency in meta-analyses. BMJ 2003;327:557-60.

17. Raymo JM, Park H, Xie Y, Yeung WJ. Marriage and family in East Asia: continuity and change. Annu Rev Sociol 2015:41:471-92.

18. Checka CM, Chun JE, Schnabel FR, Lee J, Toth H. The relationship of mammographic density and age: implications for breast cancer screening. AJR Am J Roentgenol 2012;198:W292-5.

19. Brand JS, Humphreys K, Thompson DJ, Li J, Eriksson M, Hall P, et al. Volumetric mammographic density: heritability and association with breast cancer susceptibility loci. J Natl Cancer Inst 2014;106:dju334.

20. Varghese JS, Smith PL, Folkerd E, Brown J, Leyland J, Audley T, et al. The heritability of mammographic breast density and circulating sex-hormone levels: two independent breast cancer risk factors. Cancer Epidemiol Biomarkers Prev 2012;21:2167-75.

21. Martin LJ, Melnichouk O, Guo H, Chiarelli AM, Hislop TG, Yaffe MJ, et al. Family history, mammographic density, and risk of breast cancer. Cancer Epidemiol Biomarkers Prev 2010;19:456-63.

22. Hou N, Hong S, Wang W, Olopade OI, Dignam JJ, Huo D. Hormone replacement therapy and breast cancer: heterogeneous risks by race, weight, and breast density. J Natl Cancer Inst 2013;105:1365-72.

23. Yaghjyan L, Tamimi RM, Bertrand KA, Scott CG, Jensen MR, Pankratz VS, et al. Interaction of mammographic breast density with menopausal status and postmenopausal hormone use in relation to the risk of aggressive breast cancer subtypes. Breast Cancer Res Treat 2017;165:421-31. 
Appendix Table 1. Association of breast density and cancer-related risk factors on breast cancer ${ }^{\mathrm{a}}$

\begin{tabular}{|c|c|c|c|c|c|c|c|c|}
\hline & \multicolumn{2}{|c|}{ BI-RADS 1 and $2(<50 \%)$} & \multicolumn{3}{|c|}{ BI-RADS $3(5 \%-75 \%)$} & \multicolumn{3}{|c|}{ BI-RADS $4(\geq 75 \%)$} \\
\hline & $\begin{array}{c}\text { No. of } \\
\text { cases/controls }\end{array}$ & $\begin{array}{c}\text { OR } \\
(95 \% \mathrm{CI})\end{array}$ & $\begin{array}{c}\text { No. of } \\
\text { cases/controls }\end{array}$ & OR $(95 \% \mathrm{CI})$ & $P$-value & $\begin{array}{c}\text { No. of } \\
\text { cases/controls }\end{array}$ & OR $(95 \% \mathrm{CI})$ & $P$-value \\
\hline \multicolumn{9}{|c|}{ Age at menarche (yr) } \\
\hline$<15$ & $118 / 99$ & 1 & $658 / 442$ & $1.034(0.763-1.401)$ & 0.8291 & $502 / 276$ & $1.059(0.764-1.468)$ & 0.7308 \\
\hline$\geq 15$ & $93 / 136$ & 1 & $281 / 322$ & $1.088(0.788-1.501)$ & 0.0058 & $123 / 120$ & $1.110(0.744-1.658)$ & 0.0093 \\
\hline \multicolumn{9}{|c|}{ Age at menopause (yr) } \\
\hline Premenopausal & $59 / 42$ & 1 & $548 / 380$ & $1.071(0.688-1.666)$ & 0.7618 & $511 / 310$ & $1.100(0.705-1.716)$ & 0.6746 \\
\hline$<50$ & $65 / 93$ & 1 & $199 / 233$ & $1.079(0.709-1.643)$ & 0.7225 & $69 / 65$ & $1.159(0.759-1.771)$ & 0.4937 \\
\hline$\geq 50$ & $92 / 135$ & 1 & $209 / 248$ & $0.950(0.640-1.408)$ & 0.7968 & $51 / 55$ & $0.831 \quad(0.499-1.383)$ & 0.4755 \\
\hline \multicolumn{9}{|c|}{ Number of children } \\
\hline 0 & $10 / 10$ & 1 & $146 / 60$ & $2.413(0.924-6.299)$ & 0.072 & $143 / 72$ & $1.488(0.567-3.905)$ & 0.4189 \\
\hline 1 & $30 / 32$ & 1 & $175 / 127$ & $1.042(0.583-1.864)$ & 0.8889 & $162 / 74$ & $1.317(0.711-2.438)$ & 0.3808 \\
\hline 2 or more & $172 / 200$ & 1 & $618 / 573$ & $1.024(0.802-1.308)$ & 0.8464 & $320 / 234$ & $1.122(0.841-1.496)$ & 0.4342 \\
\hline \multicolumn{9}{|c|}{ Age at first birth (yr) } \\
\hline$<28$ & $133 / 144$ & 1 & $394 / 387$ & $0.949(0.712-1.265)$ & 0.7217 & $164 / 153$ & $0.907(0.637-1.292)$ & 0.5897 \\
\hline$\geq 28$ & $69 / 79$ & 1 & $398 / 298$ & $1.199(0.826-1.742)$ & 0.3395 & $315 / 155$ & $1.546(1.035-2.310)$ & 0.0333 \\
\hline \multicolumn{9}{|c|}{ Family history of breast cancer } \\
\hline No & $163 / 212$ & 1 & $719 / 671$ & $1.051(0.825-1.338)$ & 0.6884 & $473 / 349$ & $1.052(0.801-1.380)$ & 0.7164 \\
\hline 1st degree & $37 / 24$ & 1 & $143 / 80$ & $1.156(0.632-2.112)$ & 0.6379 & $85 / 30$ & $1.890(0.921-3.880)$ & 0.0827 \\
\hline
\end{tabular}

BI-RADS, Breast Imaging-Reporting and Data System. adjusted for body mass index, smoke, drink duration, exercise, age, age at menarche, age at menopause, number of child, number of first-degree relatives with breast cancer. 